\title{
Correlation image system 3D DANTEC as a modern system for measuring deformation
}

\author{
Tomasz Domański ${ }^{1, *}$ \\ ${ }^{1}$ Czestochowa University of Technology, Institute of Mechanics and Machine Design Foundations, \\ Czestochowa, Poland, UE
}

\begin{abstract}
The work presents the possibilities created by the multi-camera 3D image correlation system. The experience is based on non-contact measurement of displacements and deformations. The measurement was used basically to estimate the deflection line of the bending beams and values of strains and displacements at various points of the cross-section. The measurement was carried out by tracking the displacements of the prepared surface of the sample. The results of the numerical analysis were also presented, which were compared with the experience carried out on the measurement stand.
\end{abstract}

Keywords: image correlation system, strains, deformations, bending test.

\section{Introduction}

The Q-400 system used with the ISTRA 4D software is a multifunctional non-contact tool for measuring the deformation of a tested object in both two- and three-dimensional coordinate systems. The principles of the system are based on relationships existing in the continuous mechanics. Dimensions and positions of the two points in the state before and after the deformation are considered. The correct operation of the system is based on the appropriate lighting and then the analysis of the light beam reflected from the surface of the observed piece before the load and in the subsequent steps of the load for consequence the deformations to appear.

The use of a non-invasive measurement method makes it possible to detect defects more quickly without the need for specialist preparation of test specimens. The advantage of using optical measurement methods of deformation or stress distribution is the ability to identify changes in the surface of the test material at microscale level, this allows early identification of the process before its dynamic development. The digital image correlation method used images of the object taken at the same time by several optical cameras with high sensitivity to deformation and vibration of the object being observed. This method of measurement is currently used increasingly to determine the components of stresses, deformations or displacements in laboratory conditions, and to identify defects in machine construction components under the influence of static loads or dynamic variables over time $[1,2]$.

\footnotetext{
* Corresponding author: domanski@imipkm.pcz.pl

Reviewers: Czestaw Kundera, Milan Vaško
} 
Measurement methods allow for easier adaptation to the measurement of parts of machine parts in their natural industrial environment under real operating conditions.

The correlation algorithm tracks the position of the same points in the source image and the distorted image (Fig. 1). To achieve this square surface containing a set of pixels, it is identified in the source image and in the position corresponding to the image after the deformation. There are many parameters that affect the accuracy of the results. They concern among other things, the size of the tracked spots, its density, The type of algorithm, the size of the set of points, the overlap of the set of points, etc. [3, 4]. Well optimized input parameters allow to obtain very accurate results.

The principle of the digital image correlation system is lighting and analysis of the intensity of light that is reflected from the surface in the state before $f(x, y)$ and after deformation $f_{l}\left(x_{1}, y_{1}\right)$. In this way, deformation measurement is carried out for small surfaces to finally obtain deformations of the actual surface of the object.

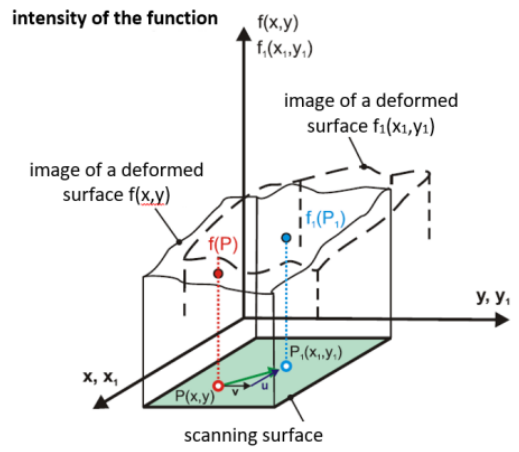

Fig. 1. Diagram of surface image analysis before and after deformation [5]

The concept of the digital image correlation method is based on the principles of continuum mechanics. The changes that occur in the dimensions and position of small linear sections between the two points in the initial $(P, Q)$ and deformed $\left(P_{l}, Q_{l}\right)$ states are analyzed.

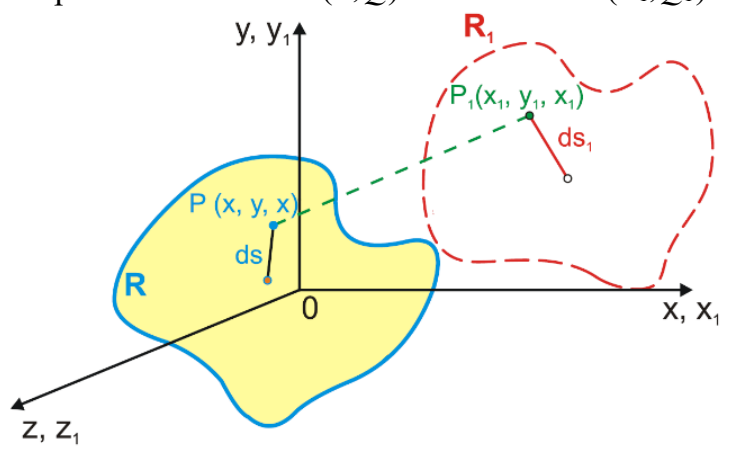

Fig. 2. Characteristic values before $(R)$ and after $\left(R_{l}\right)$ deformation [2]

$$
\begin{gathered}
P_{1}=\left(x_{1}, y_{1}, z_{1}\right)=[x+u(P), y+v(P), z+w(P)] \\
Q_{1}=\left(x_{1}+d x_{1}, y_{1}+d y_{1}, z_{1}+d z_{1}\right)= \\
{\left[\begin{array}{c}
\mathrm{x}+\mathrm{u}(\mathrm{P})+\mathrm{u}(\mathrm{Q})-\mathrm{u}(\mathrm{P})+\mathrm{dx}, \mathrm{y}+\mathrm{v}(\mathrm{P})+\mathrm{x}(\mathrm{Q}) \\
-\mathrm{v}(\mathrm{P})+\mathrm{dy}, \mathrm{z}+\mathrm{w}(\mathrm{P})+\mathrm{w}(\mathrm{Q})-\mathrm{w}(\mathrm{P})+\mathrm{dz}
\end{array}\right]}
\end{gathered}
$$

where: $u, v, w$ - represent displacements in the direction of the axis, respectively $x, y, z$

The length of the sections is determined in the following equations: 


$$
\begin{gathered}
|P Q|^{2}=(d s)^{2}=d x^{2}+d y^{2}+d z^{2} \\
\left|P_{1} Q_{1}\right|^{2}=\left(d_{1}\right)^{2}=d x_{1}^{2}+d y_{1}^{2}+d z_{1}^{2}
\end{gathered}
$$

The effect of using the formulas and mathematical transformations are components of the deformation state:

$$
\begin{gathered}
\varepsilon_{\mathrm{xx}} \cong \frac{\mathrm{du}}{\mathrm{dx}}+\frac{1}{2}\left[\left(\frac{\partial \mathrm{u}}{\partial \mathrm{x}}\right)^{2}+\left(\frac{\partial \mathrm{v}}{\partial \mathrm{x}}\right)^{2}\right] \\
\varepsilon_{\mathrm{yy}} \cong \frac{\mathrm{dv}}{\mathrm{dy}}+\frac{1}{2}\left[\left(\frac{\partial \mathrm{u}}{\partial \mathrm{y}}\right)^{2}+\left(\frac{\partial \mathrm{v}}{\partial \mathrm{y}}\right)^{2}\right] \\
\varepsilon_{\mathrm{xy}} \cong \frac{1}{2}\left(\frac{\partial \mathrm{u}}{\partial \mathrm{y}}+\frac{\partial \mathrm{v}}{\partial \mathrm{x}}\right)+\frac{1}{2}\left[\frac{\partial \mathrm{u}}{\partial \mathrm{x}} \frac{\partial \mathrm{u}}{\partial \mathrm{y}}+\frac{\partial \mathrm{v}}{\partial \mathrm{x}} \frac{\partial \mathrm{v}}{\partial \mathrm{y}}\right]
\end{gathered}
$$

\section{The research of mechanical phenomena}

Bending test is one of the basic tests to determine the mechanical properties of materials. The conditions of bending test are included in the PN-EN ISO 7438 standard. The research uses a universal testing machine Zwick\&Roell Z100 with maximum load $100 \mathrm{kN}$ and precision $1 \mathrm{~N}$ force/0.01 $\mathrm{mm}$ displacement (without a touch extensometer, fig. 3).

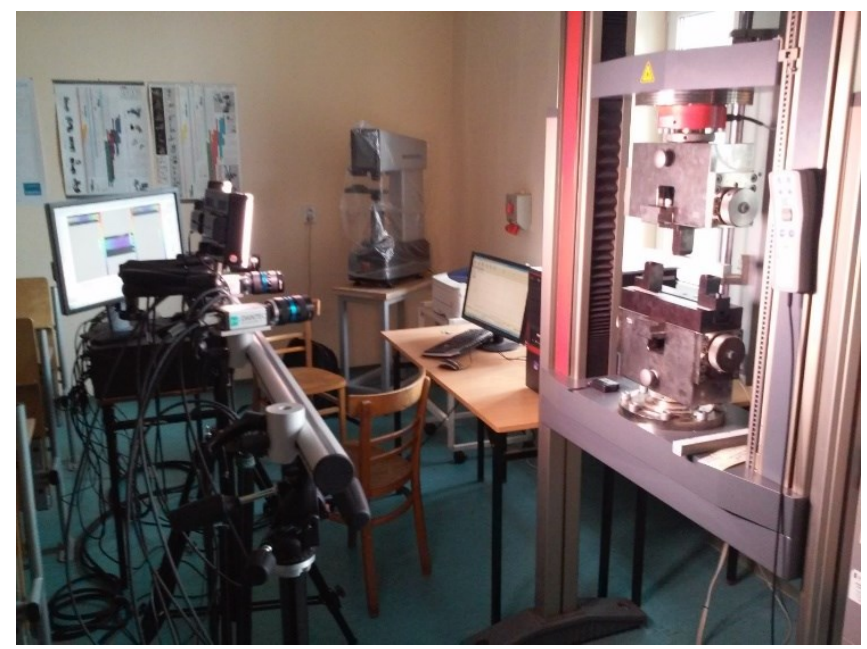

Fig. 3. System of measuring

Beam of square section $(50 \times 40 \times 3 \mathrm{~mm})$ made of aluminium PA38 loaded in subsequent attempts of forces from $10 \mathrm{kN}$ to $25 \mathrm{kN}$ with increments for every attempt what $5 \mathrm{kN}$. The Dantec system, during the bending test, took pictures with frequency $10 \mathrm{~Hz}(0,1 \mathrm{~s})$. The measuring apparatus was set at a distance of about $97 \mathrm{~cm}$ from the object under test. 


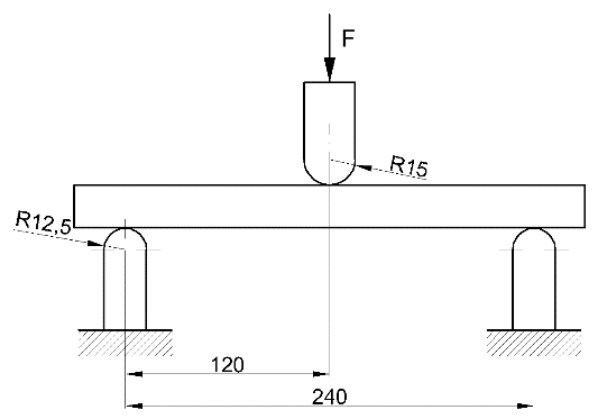

Fig. 4. Scheme of considered systems

In strength calculations, patterns based on assumptions are commonly used, although they are rarely practically met. More general bending descriptions are known that do not depart from these assumptions, but the benefits of their practical use are generally small compared to the complexity of the calculations they cause [6-8]. Flexural strength is a conventional quantity. It can be treated as a comparative quantity for the evaluation of different materials.

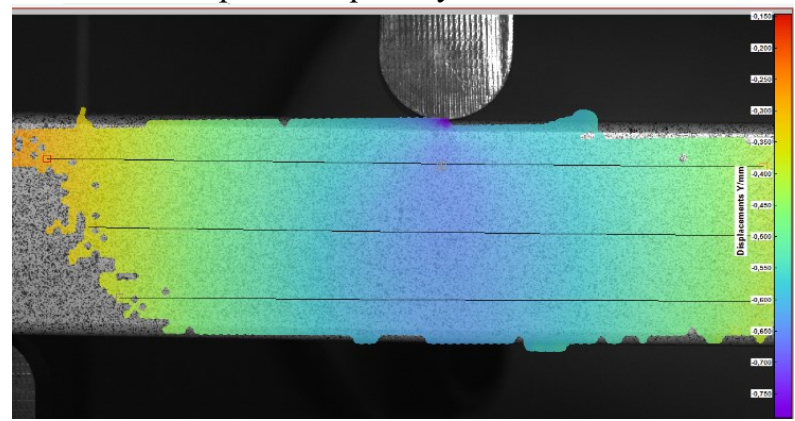

Fig. 5. Profile beam $50 \times 40 \times 3[\mathrm{~mm}]$ aluminium PA38
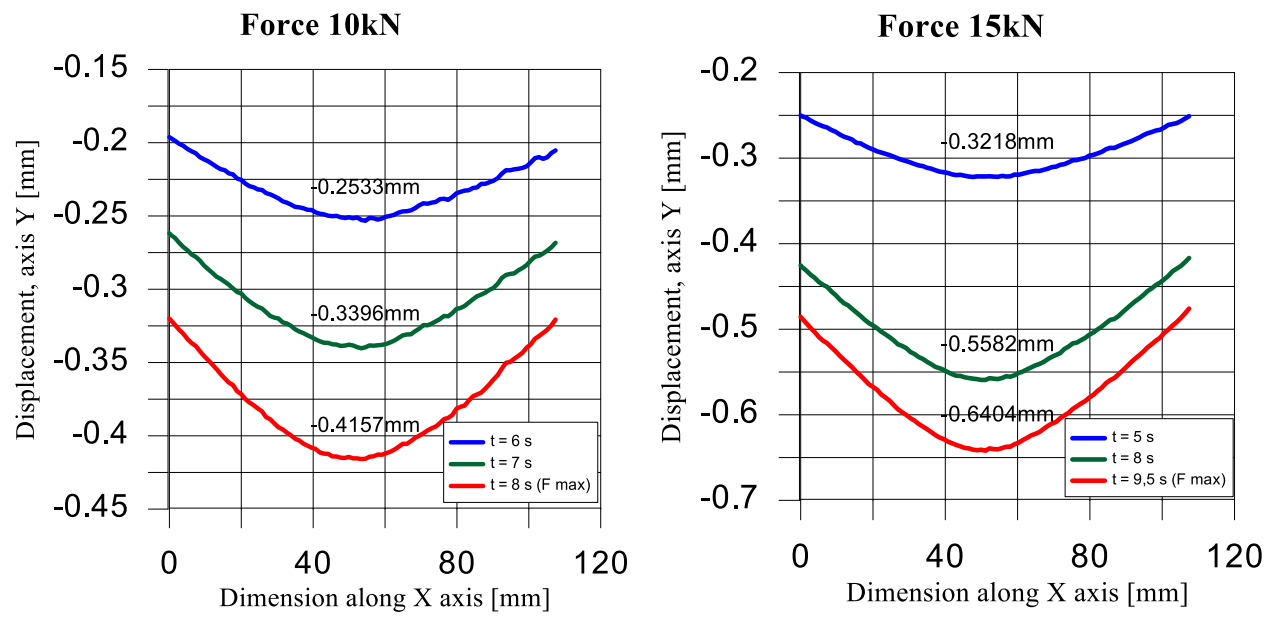

Fig. 6. Displacements distributions along the axis $X$ 

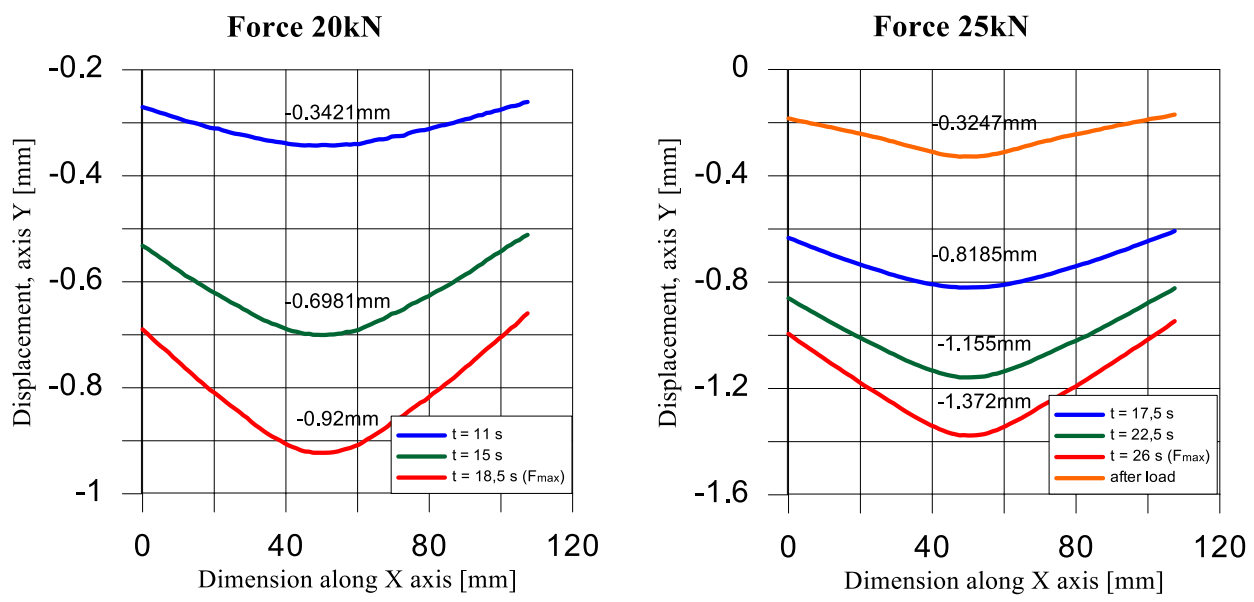

Fig. 7. Displacements distributions along the axis $X$

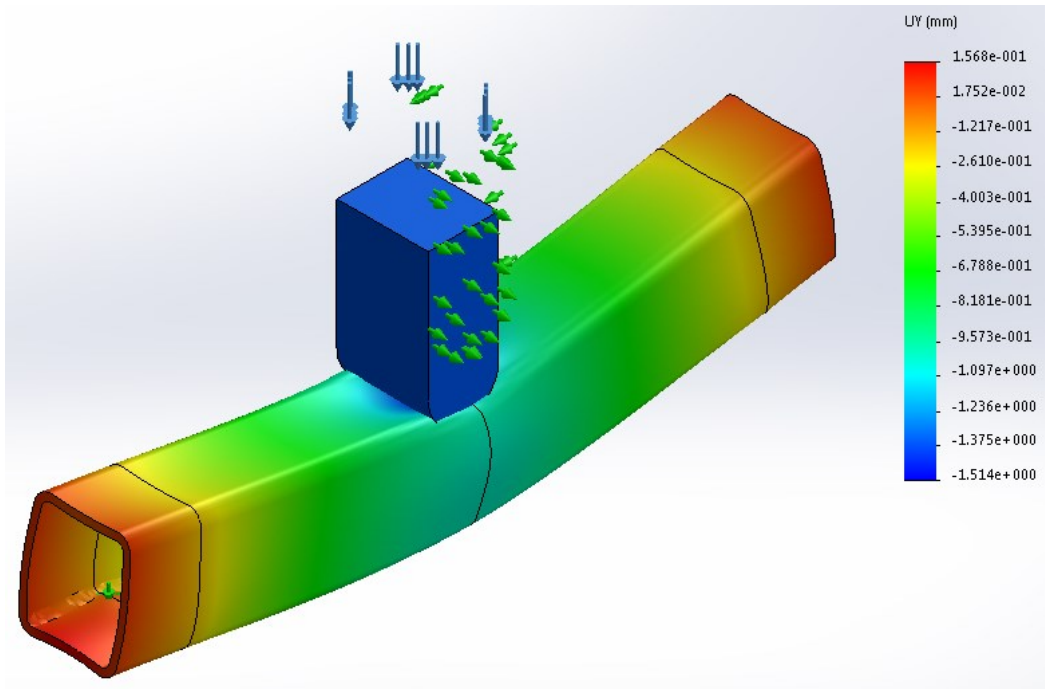

Fig. 8. The results of numerical simulation (displacement $U_{y}$ )

A numerical simulation of the bending process was carried out, the results of which are shown in Figure 8. The maximum values of displacements in nodes were determined at various stages of the loading process, and the results are presented in Table 1.

Table 1. Comparison of results for bending the beam

\begin{tabular}{|c|c|c|c|c|}
\hline \multirow{3}{*}{ Displacement } & Force $[\mathrm{kN}]$ & Dantec & SolidWorks & $\begin{array}{c}\text { Analytical } \\
\text { methods }\end{array}$ \\
\cline { 2 - 5 } & 10 & 0.4157 & 0.4084 & 0.3941 \\
\cline { 2 - 5 } & 15 & 0.6404 & 0.6172 & 0.5961 \\
\cline { 2 - 5 } & 20 & 0.92 & 0.8256 & 0.7882 \\
\hline
\end{tabular}

The distributions of displacement $\mathrm{U}_{\mathrm{y}}$ in a bending sample of the material shows figure 6-7. Marked on the image line corresponds to a central axis of the sample, wherein the graphs are compared displacements for the different forces carried out. Comparison of distributions 
displacement $U_{y}$ for the $10,15,20,25$ forces $[\mathrm{kN}]$ and at the on three different measuring lines is shown below figure 6-7.

\section{Conclusion}

After analyzing the results, a fairly large convergence of results is noticed. The values of displacements received from the experience carried out using the Dantec system are burdened with the biggest error. This may be caused by too low a frequency of making a relic during the measurement process. The results obtained from analytical calculations are very similar to those from numerical simulation.

The obtained results can be very helpful in the experimental verification of mathematical models and numerical mechanical phenomena in which deformation occurs. The use of the 3D optical correlation system allowed the analysis of displacements and deformations on the whole surface of the sample and in the control area of the measurement or on the measuring section. The use of the system allowed for the analysis of deformation during bending test.

\section{References}

1. T.C. Chu, W.F. Ranson, M.A Sutton, W.H. Peters, Application of digital-imagecorrelation techniques to experimental mechanics, Experimental Mechanics, 25(3), 232244, (1985)

2. J.D. Lord, Digital Image Correlation (DIC), Modern stress and strain analysis. A state of the art guide to measurement techniques, BSSM Technical Editors: J. Eaton Evans, J.M. Dulie-Barton, R.L. Burguete, 14-15, (2009)

3. C. Herbst, K. Splitthof, Basic of 3D Digital Image Correlation, Ulm, Dantec Dynamics $\mathrm{GmbH}$

4. K.S. Virdi, P.J. Dowling, The ultimate strength of composite columns in biaxial bending. Proc ICE;55(2):251-72, (1973)

5. T. Szymczak, P. Grzywna, Z.L. Kowalewski, Nowoczesne metody określania wytrzymałościowych właściwości materiałów konstrukcyjnych, Transport Samochodowy, 80-104, (2013)

6. K. Tateishi, T. Hanji, Low cycle fatigue strength of butt-welded steel joint by means of new testing system with image technique Int. J. Fatigue, 26, pp. 1349-1356, (2004).

7. T. Domański, Examples of modern methods of measuring deformations, MATEC Web of Conferences 157, (2018)

8. M.R. Gower, R.M. Shaw, Towards a planar cruciform specimen for biaxial characterization of polymer matrix composites, Applied Mechanics and Materials, 24$25,115-120,(2010)$ 